\title{
Desempenho de idosos em um teste de fala na presença de ruído $* * * *$
}

\author{
Performance of elderly in a speech in noise test
}

\author{
Lucila Leal Calais* \\ Ieda Chaves Pacheco Russo** \\ Alda Christina Lopes de Carvalho Borges***
}

*Fonoaudióloga. Doutoranda em Ciências pela Universidade Federal de São Paulo. Endereço para correspondência: Rua XV de

Novembro, 216 - Apto 23 - Piracicaba SP - CEP 13400-370

(calais@ig.com.br).

**Fonoaudióloga. Professora Titular do Departamento de Clínica Fonoaudiológica da Pontifícia Universidade Católica de São Paulo / Faculdade de Ciências Médicas da Santa Casa de Misericórdia de São Paulo, Diretora do Centro de Estudos dos Distúrbios da Audição (Cediau).

***Fonoaudióloga. Doutora em Distúrbios da Comunicação Humana pela Universidade Federal de São Paulo. Professora Colaboradora do Curso de Pós-Graduação em Distúrbios da Comunicação Humana: Campo Fonoaudiológico da Universidade Federal de São Paulo.

****Trabalho Realizado no Ambulatório da Disciplina de Distúrbios da Audição do Departamento de Fonoaudiologia da Universidade Federal de São Paulo.

Artigo Original de Pesquisa

Artigo Submetido a Avaliação por Pares

Conflito de Interesse: não

Recebido em 14.02.2008.

Revisado em 08.05.2008; 4.08.2008.

Aceito para Publicação em 4.08.2008.

\begin{abstract}
Background: speech perception of elderly, in silence and in the presence of background noise. Aim: to characterize and compare the hearing abilities of elderly in a monaural speech perception test, in the presence and absence of background noise (Speech Discrimination Test - SDT and Speech Perception in Noise - SPIN). Method: Participants of this study were 55 subjects of both genders, 60 years old or above, distributed in two groups: Control Group (CG), constituted by elders with no hearing loss and Study Group (SG), constituted by elders with symmetrical sensorineural hearing loss. The SPIN test was used, initially with the presentation of a word list in silence and later in the presence of Speech Noise. Results: no difference was observed between genders in the SDT and the SPIN test. Correlation with age was observed only in the SDT for SG. A significant difference was observed when comparing the performance of the groups in the SDT and SPIN test. Regarding the presence of substitutions in the articulation of words, it was observed that it occurred in both groups and was more frequent in SPIN test, especially for the SG. Conclusion: the presence of the noise during the production of speech sounds is disadvantageous for elders, independently of the presence of hearing loss, but having a higher impact for those with hearing loss problems.
\end{abstract}

Key Words: Aged; Auditory Perception; Speech Discrimination Tests; Presbycusis.

\section{Resumo}

Tema: percepção de fala no silêncio e na presença de ruído em idosos. Objetivo: caracterizar e comparar as habilidades auditivas de idosos em um teste monótico de percepção de fala, sem e com a presença de ruído competitivo (Índice Perceptual de Reconhecimento de Fala - IPRF e Fala com Ruído - F/R). Método: foram avaliados 55 sujeitos de ambos os sexos, com idade a partir de 60 anos distribuídos em grupos: Grupo Controle (GC), constituído de idosos sem perda auditiva e Grupo Estudo (GE), constituído de idosos com perda auditiva neurossensorial simétrica. Foi utilizado o Teste de Fala com Ruído, com a apresentação de uma lista de palavras primeiramente sem a presença de ruído e depois na presença de ruído do tipo Speech Noise. Resultados: não houve diferença entre homens e mulheres para os testes IPRF e F/ $\mathrm{R}$ e correlação da idade somente para o IPRF no GE. Também foi observada diferença significativa no desempenho entre os grupos nos testes IPRF e F/R. Com relação à presença das trocas articulatórias, foi observado que elas ocorreram nos dois grupos estudados, sendo mais freqüente no teste $\mathrm{F} / \mathrm{R} \mathrm{e}$, principalmente, para o grupo estudo. Conclusão: a presença do ruído juntamente com os sons de fala é prejudicial para os idosos, independente da presença da perda auditiva, sendo o impacto maior para aqueles que a possuem. Palavras-Chave: Idoso; Percepção Auditiva; Testes de Discriminação da Fala; Presbiacusia. 


\section{Introduction}

Communication is part of the life of all the human beings, but mainly in the development decline, hearing can be fundamental to obtain better health quality. The elderly, with several functions altered by age, can be benefited if hearing and comprehension ability can be maintained.

In clinical routine, a common complaint revealed by the elderly is regarding the difficulty of the understanding of the spoken language, mainly in situations in which there is noise in the environment, fact mentioned in other prior studies (1-3). Moreover, the reported difficulty can be bigger than expected considering the degree of the evidenced hearing loss at the audiological evaluation $(4,5)$.

With regards the diagnostic, the conventional tests used represent a microscopic vision of auditory function (6-8), and the evaluation of speech recognition in the presence of a competitive stimulation, as for example, noise, would be a more real manner to evaluate hearing (9-11). Moreover, this information could justify, at least in part, the complaints of patients and support on the rehabilitation plan.

The study about the interference of noise in speech recognition has been conducted by several authors $(8-10,12,13)$ with the findings of the harmful effect of noise in the indices of recognition.

Giving the exposed facts, the present study had as objective to compare the performance in the Speech Perception in Noise test of elderly with and without hearing loss.

\section{Methods}

\section{Participants}

A retrospective study with data collected from a handbook of patients of the Clinic of Hearing Disorders Discipline of the Speech and Hearing Department of the Federal University of São Paulo (Universidade Federal de Sao Paulo) was carried through, on the period from September of 2004 to August of 2005. This study was approved by the Committee of Ethics in Research of the Federal University of São Paulo under number 1784/07.

The casuistry was constituted by 55 individuals, being $49(89.1 \%)$ of the study group (RG) and $6(10.9 \%$ ) of the control group (CG). All the individuals were seniors, as established by the law number 10,741/03 (14).

The study group was composed by 43 women $(87.76 \%)$ and six men (12.24\%) with minimum age of
61 years and maximum age of 87 (average of 72.41 years). The individuals of this group presented tympanometric curve of the type A(15), symmetrical descendant neurosensorial hearing loss with tonal threshold below at least $30 \mathrm{~dB}$ in frequencies of 6 $\mathrm{kHz}$ and $8 \mathrm{kHz}$ and maximum limit of $60 \mathrm{~dB}$ of average tonal threshold of the frequencies of $500 \mathrm{~Hz}, 1 \mathrm{kHz}$ and $2 \mathrm{kHz}$.

The control group was composed by six women with minimum age of 60 years and maximum age of 72 (average of 65 years). The seniors of this group also presented tympanometric curve of the type A, but the audiometric thresholds from $250 \mathrm{~Hz}$ to 8 $\mathrm{kHz}$ were inside normal limits (up to $25 \mathrm{~dB} N A$ ). The composition of this control group was exclusively done by individuals who presented all tonal thresholds inside normal limits, fact not so frequent on the elderly population what disabled the age comparison with the study group.

\section{Procedures}

The following data were obtained from the handbooks of the participants:

. identification data: age and gender;

. score on the Speech Discrimination Test (SDT), one syllable words list, such for the right ear as for the left ear;

. score on the Speech Perception in Noise test (SPIN) such for the right ear as for the left ear.

The speech audiometry of the analyzed cases was carried through in a acoustically treated booth, using the two channels audiometers GSI-64 and ORBITER-MADSEN 922, with supra-aural phones TDH-39 suitable to cushion MX-41 calibrated in accordance with the ISO 8253-1 norm, 1989 (16).

The Speech Discrimination Test (SDT) and the Speech Perception in Noise test (SPIN) were carried through using a COMPACT DISC player from Toshiba, model CDP 4147, connected to the audiometer. The second band of the $\mathrm{CD}$, volume 1 , that comes with the Central Auditory Processing Evaluation Manual book (17) were used on the two tests, with ipsilateral competitive noise of the Speech Noise added on the SPIN test. The choice for the Speech Noise occurred for it being a filtered white noise in the band of the low and medium frequencies, simulating the average speech spectrum. The signal/ noise relation used was $+5 \mathrm{~dB}$. First, the test on the right ear was applied and then on the left ear, being registered, in percentage, the total number of correctly repeated words in each one of the tests. 
Additionally, a qualitative analysis of the scores, errors and omissions on SDT and SPIN tests was carried through, using the Confusion Matrixes (CM), adapted for the Brazilian Portuguese by Helou, Novaes (2005) (18). In the Confusion Matrixes the following series of traces are establish as base for the consonant classification:

1. Voicing - in articulation terms: the vocal folds do not vibrate on phonemes /p/, /t/, /k/, /f/, /tS/, /s/, /S/ and do vibrate on /b/, /d/, /g/, /v/, /dZ/, /z/, /Z/, /m/, $/ \mathrm{n} /$.

2. Nasalization to articulate $/ \mathrm{m} /$ and $/ \mathrm{n} /$.

3. Friction - type of frictional turbulence of noise that distinguishes /f/, /tS/, /s/, /S/, /v/, /dZ/, /z/, /Z/ from consonants /p/, /t/, /k/, /b/, /d/, /g/, /m/, /n/. 4. Duration - difference between /s/, /S/, /z/, /Z/ and the others 12 consonants.

5. Point of articulation - /p/, /b/, /f/, /v/, /m/ as frontals; /t/, /d/, /tS/, /s/, /dZ/, /z/, /n/ as medium and $/ \mathrm{k} /, / \mathrm{g} /, / \mathrm{S} /, / \mathrm{Z} /$ as posterior consonants.

This way a table is filled, in which the column to the left refers to the list of presented consonants and the horizontal line to mark the response of the listener. In the case of omission the marking is carried through in the column to the extreme right. On the bottom it is computed the number of presentations, scores and omissions and the shifts, scores and omissions percentage, which were presented in this study.

Each one of the lists of one syllable words presented to each participant contained 36 presentations (consonant phonemes), being first presented on the right ear and then on the left ear and on the determined situations (with and without noise). Thus, the $100 \%$ score would refer to the rightness of 36 phonemes and as the number of correct response diminishes, also does the percentage. It is important to highlight that in this analysis the shifts that involve vowels or sounds that represent vowels or even the addition of phonemes are not considered.
Regarding the statistical analysis of the results the non-parametric tests of Mann-whitney were used. This test is used when there are independent samples and it is desired to compare two-by-two variables. The Spearman Correlation was used to verify the degree of association between two variables. The adopted significance level was of $0.05(5 \%)$ with Confidence Intervals of $95 \%$.

\section{Results}

In all the work, the analyses were made considering both ears, totalizing 98 in the study group (SG) and 12 in the control group (CG) for not having significant differences between them ( $\mathrm{p}$ value $>0.05$ ).

In the study group, regarding the female and male gender for the SDT, the scores were $87.63 \%$ and $88.67 \%$, whereas for the SPIN was of $73,49 \%$ and $80 \%$, being these differences not statistically significant (p-valor $=0,539$ and 0,144 ).

Regarding the correlation of the speech tests with age for study group (SG) statistically significant difference were found for the SDT ( $p$ valor $=0,018)$ and a trend to a similar situation for the SPIN test ( $p$-valor=0,059). The same did not occur in the control group (CG) with p-values of 0,515 for SDT and 0,890 for the SPIN.

Comparison data between the SG and the CG for scores on SDT and SPIN test and the shifts, scores and omissions in accordance with the Confusion Matrixes (18) are shown in Table 1.

In Table 2 it is possible to visualize the comparison of the mean average punctuation between SDT and SPIN tests of the study and control groups.

In Table 3 the comparison between the shift, score and omission of phonemes on SDT and SPIN tests of the study and control groups according to the Confusion Matrixes (18) is exposed. 
TABLE 1. Comparison between SG and CG on the percentage scores of SDT and SPIN tests and also shifts, scores and omissions according the Confusion Matrixes.

\begin{tabular}{|c|c|c|c|c|c|}
\hline Groups & & Mean & Median & Standard Deviation & p-value \\
\hline \multirow{2}{*}{ SDT } & SG & 87,76 & 88 & 5,38 & \multirow{2}{*}{$0,001 *$} \\
\hline & CG & 93,33 & 96 & 4,92 & \\
\hline \multirow{2}{*}{ SPIN } & SG & 74,29 & 78 & 12,45 & \multirow{2}{*}{$0,010^{*}$} \\
\hline & CG & 83,33 & 84 & 6,11 & \\
\hline \multirow{2}{*}{ Shift SDT } & SG & 6,41 & 5,5 & 3,90 & \multirow{2}{*}{$0,002^{*}$} \\
\hline & GC & 3,25 & 2,8 & 4,07 & \\
\hline \multirow{2}{*}{ Shift SPIN } & SG & 13,93 & 11,1 & 7,86 & \multirow{2}{*}{$0,016^{*}$} \\
\hline & CG & 8,78 & 8,3 & 4,57 & \\
\hline \multirow{2}{*}{ Score SDT } & SG & 90,50 & 91,7 & 4,49 & \multirow{2}{*}{$<0,001$} \\
\hline & CG & 95,35 & 97,2 & 4,64 & \\
\hline \multirow{2}{*}{ Score SPIN } & SG & 80,74 & 83,3 & 9,84 & \multirow{2}{*}{$0,007^{*}$} \\
\hline & CG & 88,18 & 88,9 & 4,92 & \\
\hline \multirow{2}{*}{ Omission SDT } & SG & 3,08 & 2,8 & 2,68 & \multirow{2}{*}{$0,037 *$} \\
\hline & CG & 1,40 & 1,4 & 1,46 & \\
\hline \multirow{2}{*}{ Omission SPIN } & SG & 5,82 & 5,5 & 5,51 & \multirow{2}{*}{0,113} \\
\hline & CG & 3,24 & 2,8 & 1,58 & \\
\hline
\end{tabular}

TABLE 2. Comparison of the performance (in percentage) between SDT and SPIN test of SG and CG.

\begin{tabular}{ccccc}
\hline \multirow{2}{*}{ Comparison } & \multicolumn{2}{c}{ SG } & \multicolumn{2}{c}{ CG } \\
& SDT & SPIN & SDT & SPIN \\
\hline Mean & 87,76 & 74,29 & 93,33 & 83,33 \\
Median & 88 & 78 & 96 & 84 \\
Standard Deviation & 5,38 & 12,45 & 4,92 & 6,11 \\
p-value & \multicolumn{2}{c}{$0,001^{*}$} & \multicolumn{2}{c}{$0,002^{*}$} \\
\hline
\end{tabular}

TABLE 3. Comparison of percentage scores, omissions and shifts on the SDT and SPIN tests of the study and control groups.

\begin{tabular}{|c|c|c|c|c|c|c|}
\hline Group & & & Mean & Median & Standard Deviation & $\mathrm{p}$-value \\
\hline \multirow{6}{*}{ Study } & \multirow{2}{*}{ Shift (\%) } & SDT & 6,41 & 5,5 & 3,9 & \multirow{2}{*}{$<0,001^{\prime}$} \\
\hline & & SPIN & 13,93 & 11,1 & 7,86 & \\
\hline & \multirow{2}{*}{ Score $(\%)$} & SDT & 90,5 & 91,7 & 4,49 & \multirow{2}{*}{$<0,001^{\prime}$} \\
\hline & & SPIN & 80,74 & 83,3 & 9,84 & \\
\hline & \multirow{2}{*}{ Omission (\%) } & SDT & 3,08 & 2,8 & 2,68 & \multirow{2}{*}{$<0,001$} \\
\hline & & SPIN & 5,82 & 5,5 & 5,51 & \\
\hline \multirow{6}{*}{ Control } & \multirow[b]{2}{*}{ Shift (\%) } & SDT & 3,25 & 2,8 & 4,07 & \multirow{2}{*}{$0,002^{*}$} \\
\hline & & SPIN & 8,78 & 8,3 & 4,57 & \\
\hline & \multirow{2}{*}{ Score $(\%)$} & SDT & 95,35 & 97,2 & 4,64 & \multirow{2}{*}{$0,002^{*}$} \\
\hline & & SPIN & 88,18 & 88,9 & 4,92 & \\
\hline & \multirow{2}{*}{ Omission (\%) } & SDT & 1,4 & 1,4 & 1,46 & \multirow{2}{*}{$0,037 *$} \\
\hline & & SPIN & 3,24 & 2,8 & 1,58 & \\
\hline
\end{tabular}




\section{Discussion}

The statistical analysis revealed that there was no statistically significant difference on the performance of SDT and SPIN tests between men and women of the study group. In the control group this variable was not considered because of the fact that all participants were women.

Among the analyzed studies, only one of them (9) considered the variable gender, disclosing, as well as in the present study, absence of significant differences between men and women. Perhaps this situation disclosed that the existing biophysiological differences between men and women, with respect the elderly, were not reflected on the performance on speech tests conducted and, for this reason, this aspect is not frequently explored in literature.

With regards to the correlation between age and the speech tests, in the study group there was statistically significant negative correlation between SDT and age, that is, as bigger the age worse the score on the test. When considering SPIN test, it can only be referred that there is a trend to a similar correlation. In the control group, correlation between age and considered tests was not observed.

The observed differences raise the hypothesis that, in the study group, on the more favorable situation of communication (without noise), the increase on age reflected in smaller ability in understanding the speech sounds. Regarding the less favorable communication situation (with noise), the age did not intervene on the performance of the test and even younger seniors demonstrated to be sensible on a similar way to the negative noise interference in speech sound recognition. This way, SDT was presented to be more useful in disclosing the interference of age in seniors with hearing loss.

In the case of the control group, the lack of correlation of age might have occurred due to the average age, as well as the age range, being inferior to the ones of the study group. That is, the participants of the control group were younger seniors (majority in the age range between 60 and 66 years). Moreover, all the participants of the control group presented tonal thresholds inside normal limits, what might also have influenced this result.

Other studies $(12,19)$ also observed the interference of age in the evaluation of speech recognition without noise, but the enclosed age range differed from the one of the present study (from 40 to 80 years), or even lists of two syllable, and not one syllable words were used which offer more acoustics tips.

The differences between study and control groups were also evidenced in the comparison of scores on the SDT and SPIN and also on the shift, scores and omission of the Confusion Matrixes (18) analysis (Table 1). All considered variables presented p-values smaller than 0.05 , with exception of the comparison of the omission scores on the SPIN test ( $\mathrm{p}$-value 0,113 ). The worst general performance would be expected for the study group once that all the participants of that group presented hearing loss, even thought on high frequencies, besides mean age superior to the ones of the control group. However, the similar omission scores on speech sounds with noise between the groups manifest that this condition is more frequent with age advancing, even in seniors with preserved peripheral hearing.

Studies in literature (8-9) that compared the performance between groups of individuals (young e elderly) also found differences between them, with worst performance of the senior participants presenting presbyacusis or without hearing loss. However, they used groups with characteristics of distinct audiometric tonal thresholds and age and/ or methodologies that differed from the present study.

Regarding the impact of the presence of noise on speech comprehension, in Table 2, it is possible to visualize the comparison of each group performance on the SDT and SPIN tests, being the difference statistically significant for both, with greater impact for the study group. This fact disclosed that the speech material presented simultaneously with noise resulted on a negative impact for all participants, even for the younger and with good hearing acuity ones. That is, the performance on speech tests, at least in the presence of noise, cannot be justified only by tonal thresholds.

In literature the presentation of the difference on the performance on speech recognition tests with and without noise in seniors with tonal thresholds inside normal limits(9) can be found, on a more significant way, in seniors with high frequency hearing loss (8).

The speech comprehension is a complex process that does not only involves the perception and identification of speech sounds and isolated words, but also the successive integration of the heard words, phrases and sentences that together walk for a precise and coherent representation of the meaning of the message that is being reported (4). 
Besides the speech comprehension complexity, mainly in situations of difficult listening, there are other aspects involved on the precise comprehension of the message as, for example, central auditory system and cognitive aspects. Several authors (2-5) affirmed the evolvement of these other aspects and called the attention for the condition that seniors present with the deterioration of these systems, beyond the auditory one. This fact can contribute for the increase of comprehension difficulties that the individual shows with the passing of the years.

With regards to the comparison of the shifts, scores and omission presented on the speech tests (Table 3) by the study and control groups are statistically significant different in all comparisons, being worst the performance on SPIN test with greater percentage of shift and omissions and smaller percentage of scores. Once more, the negative component of the presence of noise on the performance of speech tests is demonstrated, what justifies the frequent complaint in the clinical routine by seniors who listen to the sounds without great difficulties, but do not understand the heard words, mainly in situations in which there is noise on the background.

\section{Conclusion}

Ahead of the previously presented results, the following can be concluded:

. elderly presented damage on speech sounds recognition in the presence of competitive noise, even when presenting tonal thresholds inside normal limits;

\section{References}

1. Viude A. Fatores associados a presbiacusia em idosos [Tese]. São Paulo: Universidade de São Paulo; 2002.

2. Gates GA, Mills JH. Presbycusis. Lancet. 2005;366(9491):1111-20.

3. Rados C. Sound advice about age-related hearing loss. FDA Cons 2005;39(3). Disponível em http://www.fda.gov/ fdac/features/2005/305_hear.html.

4. Schneider BA, Daneman M, Pichora-Fuller MK. Listening in aging adults: from discourse comprehension to psychoacoustic. Can J Exp Psychol. 2002;56(3):139-52.

5. Pichora-Fuller MK. Cognitive aging and auditory information processing. Int J Audiol. 2003;42 Suppl 2S:2632.
In literature, several studies $(8-10,12,13)$ verified the harmful effect of the noise on the recognition of speech sounds, but they carried through analysis distinct to the present study ones.

Finalizing, the described study focused on data that might be relevant to literature with regard to the ability of speech recognition of senior listeners with and without the presence of a competitive noise. It demonstrated that, tonal thresholds inside normal limits are not enough to guarantee an adequate recognition of speech sounds in situations where there is noise with the speech sounds that are desired to be comprehend.

It would be interesting that more national studies considering the interference of competitive stimulations in the understanding the speech sounds for a better understanding of the impact of aging on the communicative performance and a more realistic way to register the speech comprehension difficulty complaints in situations of daily life. Moreover, it can open ways for more adequate performances in auditory rehabilitation and, consequently, improvements on the elderly health quality.

. the negative impact of the presence of noise together with the speech sounds was significantly bigger for the group of seniors with hearing loss; . the increase of the age influenced on a negative way the recognition of speech sounds, however, without the presence of noise and in seniors who presented hearing loss.

6. Corrêa GF, Russo ICP. Autopercepção do handcap em deficientes auditivos adultos e idosos. Rev CEFAC. 1999;1(1):54-63.

7. Plomp R. The Intelligent Ear: on the nature of sand and perception. London Lawrence Erlbaum Associates Publishers; 2002. p. 1-11.

8. Caporali SA, Silva JA. Reconhecimento de fala no ruído em jovens e idosos com perda auditiva. Rev Bras Otorrinolaringol. 2004;70(4):525-32.

9. Duarte VG. O efeito do ruído na percepção de fala de indivíduos ouvintes jovens e idosos. [Dissertação]. São Paulo: Pontifícia Universidade Católica de São Paulo; 1998.

10. Kenyon EL, Leidenheim SE, Zwillenberg S. Speech discrimination in sensorineural hearing loss patient: how is it affected by background noise? Mil Med. 1998;163(9):647-50. 
11. Pichora-Fuller MK, Souza PE. Effects of aging on auditory processing of speech. Int J Audiol. 2003;42 Suppl 2S:11-6.

12. Studebaker GA, Sherbecoe RL, McDaniel DM, Gwaltney CA. Monosyllabic word recognition at higher-than-normal speech and noise levels. J. Acoust. Soc. Am. $1999 ; 105(4): 2431-44$

13. Souza PE, Boike KT, Witherell K, Tremblay K. Prediction of speech recognition from audibility in older listeners with hearing loss: effects of age, amplification, and background noise. J. Am Acad Audiol. 2007;18(1):5465 .

14. Brasil. Lei n. 10.741 de $1^{\circ}$ de outubro de 2003. Dispõe sobre o Estatuto do Idoso e dá outras providências. Diário Oficial da República Federativa do Brasil, Brasília (DF); 2003 out 3.

15. Jerger J. Clinical experience with impedance audiometry. Arch Otolaryngol. 1970;92:311-24.
16. International Standards Organization. Acoustics Audiometric test methods. Part I: Basic pure tone air and bone conduction threshold audiometry. Geneva, Switzerland. ISO 8253-1, 1989.

17. Pereira LD, Shochat E. Fala com ruído (teste 1). In: Pereira LD, Shochat E. Processamento auditivo centralmanual de avaliação. São Paulo: Lovise; 1997. p. 99-102.

18. Helou LF, Novaes BC. Utilização da matriz de confusão na indicação de aparelho de amplificação sonora individual. Distúrb. comun. 2005;17(2):203-13.

19. Martini A, Mazzoli M, Rosignoli M, Trevisi P, Maggi S, Enzi G, Crepaldi C. Hearing in the elderly: a population study. Audiology. 2001;40(6):285-93. 